\title{
Is me-search a kiss of death in mental health research?
}

\author{
Andrew R. Devendorf, B.A \\ University of South Florida, Department of \\ Psychology, Tampa, FL.
}

Applicants to graduate school in clinical psychology are warned against disclosing something in their application that could be the "kiss of death," information that by itself causes admissions committees to reject otherwise strong applicants. Specifically, several renowned authorities warn applicants against disclosing a lived experience with, or close connection to, psychopathology. This state of affairs seems counterintuitive. At least some people who pursue research in clinical psychology do so, in part, because they have a lived experience with mental illness. This pursuit is termed "self-relevant" research, which is also known by the pejorative label, "mesearch." Mental health professionals with lived experience are sometimes referred to as "prosumers." There are anecdotal accounts of stigma toward self-relevant research in clinical psychology, but despite the important professional stakes at-hand (e.g., gaining admissions into a graduate program), we lack systematic documentation of such experiences. To fill this research gap, I use a Scholarly Personal Narrative to facilitate a scholarly conversation about this topic. I reflect upon my own experiences with stigma for when I, a depression researcher, shared my personal connections to depression in my family. This narrative calls for inquiry on self-relevant research and questions biases against this pursuit, for example, the assumption that self-relevant research hinders objectivity. Noting exemplars of people conducting self-relevant research in clinical psychology (e.g., Marsha Linehan), encouraging a more robust practice of self-relevant research may help combat psychopathology stigma.

Impact Statement: It is not uncommon for researchers who have direct or indirect experience with a mental illness to study that same mental illness. This is called "mesearch," a pejorative term that implies pursuing a personally relevant research topic biases objectivity or is suspect in some other way. However, notable examples (e.g., Marsha Linehan) combat this stigmatizing notion, and acceptance and disclosure of me-search can be positive for students, scientists, and clients with mental illness, alike.

Keywords: Prosumer, Stigma, Me-search, Mental health, Suicide

Corresponding Author: Andrew R. Devendorf, andrewdevendorf@gmail.com

Acknowledgements: I would like to thank everyone who provided me feedback on early drafts of this manuscript. I appreciate the ongoing support of my mentor, Jonathan Rottenberg, for his encouragement and detailed feedback. I also appreciated the insights of Vanessa Panaite, Julia McDonald, Ben Listyg, Curtis Puryear, and the members of the Mood and Emotion Lab at University of South Florida.

(C) 2020, American Psychological Association. This paper is not the copy of record and may not exactly replicate the final, authoritative version of the article. Please do not copy or cite without authors' permission. The final article will be available, upon publication, via its DOI: $10.1037 /$ ser0000507 


\section{Is me-search a kiss of death in clinical psychology research?}

Students interested in pursuing a graduate degree in psychology are often presented with advice on the "do's" and "don'ts" of application materials. For instance, applicants commonly receive advice to avoid making a mistake that is a "kiss of death." A "kiss of death" refers to providing types of information that cause admissions committees to reject otherwise strong applicants. The term was coined by a survey study of 457 psychology graduate programs, which offers advice to prospective students on how they can matriculate into these programs (Appleby \& Appleby, 2006). The study concludes that "the discussion of a personal mental health problem is likely to decrease an applicant's chances of acceptance into a program" (p. 20), with the rationale that the approach may read as a sob story, involve self-interest (e.g., a researcher is primarily interested in learning about themselves), or indicate emotional instability (Appleby \& Appleby, 2006). Several popular resources for gaining admissions into clinical psychology programs have endorsed this sentiment (e.g., Prinstein, 2017; Prinstein, Choukas-Bradley, \& Guan, 2013; Association for Behavioral and Cognitive Therapies, 2019; Indiana University - Purdue University Indianapolis, 2019). In "Mitch's Uncensored Advice," one of the most renowned guides used by students and faculty, it is stated that clinical psychology applicants are "often screened out" for disclosing their own psychopathology (Prinstein, 2017, p. 24). Simply put, referencing one's mental health experiences may be a kiss of death in clinical psychology.

This is an odd state of affairs. At least some people who pursue research in clinical psychology do so, in part, because they have a close relationship to, or identify with, their mental health (MH) research area. This pursuit will be termed "self-relevant" (SR) research, defined as research with, about, or connected to one's identity or positionality in which the researcher has a personal investment in the topic (e.g., a lived experience with, or close connection to, a MH problem; Gardner et al., 2017). The term SR research is also commonly known as "me-search," as in the title of this manuscript. However, me-search has been used pejoratively to attack the credibility of self-relevant researchers. For example, the term me-search is associated with negative connotations of self-indulgence and lacking objectivity (Gardner et al., 2017). To favor a more descriptive and unbiased term, this paper uses the term SR research.

While there are certainly times when self-disclosure of a $\mathrm{MH}$ problem distracts from a personal statement's focus, which traditionally rests on career goals, accomplishments, and acquired skills, Appleby and Appleby's (2006) survey provided a telling quotation that implies biases against SR research on MH topics (coined SR-MH research):

"a [kiss of death] may occur 'when students highlight how they were drawn to graduate study because of significant personal problems or trauma. Graduate school is an academic/career path, not a personal treatment or intervention for problems." (Appleby \& Appleby, p. 20)

Given the important professional stakes at-hand, like gaining admissions into graduate school, a commentary on the following questions is needed. Is there evidence that admissions committees discriminate (e.g., reject) against applicants who disclose their SR-MH research? Are biases against SR research stronger toward SR-MH research (e.g., a researcher who studies depression because they have a family member with depression), compared to other forms of SR research (e.g., a researcher studies Alzheimer's Disease because they have a family member with Alzheimer's Disease)? What are the positives about pursuing and sharing SR-MH research? With a recent trend of graduate programs reflecting on the biases of their selection procedures, even going so far as to remove the Graduate Record Examinations (GRE) as a requirement (Langin, 2019), it is timely to address the issue of SR-MH research bias. 


\section{Aims}

Because there is almost no formalized psychological research on this topic, this manuscript aims to start a scholarly conversation about these questions. However, the absence of empirical work does not mean that there is an absence of stigma, defined as prejudice and discrimination that emerges when the general public endorses specific stereotypes (Rüsch, Angermeyer, \& Corrigan, 2005). With this notable gap in the literature, I utilize a Scholarly Personal Narrative (SPN; see Bradley \& Nash, 2011) to encourage further scholarly discussion. SPNs are like autoethnographies and can provide an in-depth look at an experience, a social condition, and other profession-related phenomena. In this SPN, I share my experiences with stigma as a Ph.D. student in clinical psychology for disclosing my personal links to depression and suicide in my family. I challenge this possible stigma through questioning notions that are commonly stated against SR research. I conclude by providing a nuanced understanding of SR-MH research, highlighting disclosure of SR-MH research can be powerful to combating stigma toward $\mathrm{MH}$ problems.

\section{Self-Disclosure and Stigma - A Personal Narrative}

Six months before entering my program, my older brother, Matt, died by suicide. He was only 27 and had battled depression most of his life. Growing up with Matt galvanized my interest in "solving" the depression epidemic. What factors might initiate Matt's recovery? Why didn't Matt feel safe sharing his depression or seeking help? My drive to study depression was not solely to help Matt. Rather, Matt's pain gave me insight into the experiences of more than 300 million people worldwide (World Health Organization, 2017). Recognizing the societal burden of depression, I turned to science to advance our understandings of depression, recovery, and mental health stigma reduction. In my eyes, my personal experiences propelled me to understanding the real-life implications of depression and emboldened me to rigorously tackle the issue.

Like many applicants, I researched tips to optimize my chances for being admitted into a clinical psychology Ph.D. program. It seemed most application resources (see Table 1) had the same advice, "Don't disclose your personal relationship to psychopathology." I took this advice to heart and consciously avoided discussing how my experiences with depression in my family informed my scholarly research interests on depression. To my joy, I was admitted into Ph.D. programs for clinical psychology. One week after accepting my offer, Matt passed away. Matt's death is my most significant loss. His suicide intensified an existing desire to research depression and decrease stigma. So, when several research scholarship applications asked to "discuss the development of [my] interest in psychology," I felt it germane to discuss my personal relationship to my research area through referencing my brother. When writing this statement, I sought candid feedback from my mentors. I asked them if my story was too informal, inappropriate, or excessive. They both said "no" and encouraged me that my story was brave and compelling.

Unfortunately, I received no scholarships that year. I took the rejection as a sign that I lacked the requisite qualifications. Maybe I needed more publications? I was wrong. A committee member from one of the scholarships offered me in-person feedback. When we met, I was shocked to learn that my selfdisclosure disqualified me from the scholarship. My SR-MH research disclosure acted as a kiss of death. They mentioned the other committee members expressed discomfort in reading my application, "He has the awards, publications, and research experience, why would he feel the need to share this?" These members reportedly voiced disapproval for my "oversharing" and were unwilling to discuss my application further. They viewed my personal experiences as a potential bias harming my objectivity as a young scientist. I felt defeated. Had I been told I needed more publications or other experience I would 
have understood. Instead, I was advised to conceal a core part of my identity as a researcher. The implication was that, to be successful, I would need to hide my experiences with depression and suicide. This was stigma; this was discrimination against my self-disclosure of my relationship to a mental health problem.

Table 1. Select Quotes from Popular Graduate School Resources that Advise Against Disclosure of Mental Health Problems

\begin{tabular}{|c|c|c|}
\hline Title & Quote & Citation \\
\hline $\begin{array}{l}\text { Kisses of Death in the } \\
\text { Graduate School Application } \\
\text { Process }\end{array}$ & $\begin{array}{l}\text { "Avoid references to your mental health. Such statements } \\
\text { could create the impression you may be unable to function } \\
\text { as a successful graduate student." }\end{array}$ & $\begin{array}{l}\text { Appleby \& } \\
\text { Appleby, 2006, p. } \\
23\end{array}$ \\
\hline $\begin{array}{l}\text { Mitch's Uncensored Advice } \\
\text { for Applying to Graduate } \\
\text { School in Clinical Psychology } \\
\text { Deciding to Apply and } \\
\text { Successfully Gaining } \\
\text { Admission to Graduate } \\
\text { Schools in Psychology }\end{array}$ & $\begin{array}{l}\text { *'I believe there are three main reasons why an } \\
\text { application would not make it past this hurdle... [The third } \\
\text { reason is] the application contains information that is } \\
\text { widely inappropriate and unprofessional. Applicants who } \\
\text { disclose their own psychopathology, for example, are } \\
\text { often 'screened out' at this stage" }\end{array}$ & $\begin{array}{l}\text { Prinstein, 2017, p. } \\
24 \\
\text { Prinstein, } \\
\text { Choukas-Bradley } \\
\& \text { Guan, 2013, p. } \\
37\end{array}$ \\
\hline $\begin{array}{l}\text { Getting into Graduate School } \\
\text { [Video file] }\end{array}$ & $\begin{array}{l}\text { "Going too much in-depth into a story about your own } \\
\text { personal therapy or a family member's mental health can } \\
\text { sometimes take the focus away from your academic goals } \\
\text { and interests." }\end{array}$ & $\begin{array}{l}\text { Association for } \\
\text { Behavioral and } \\
\text { Cognitive } \\
\text { Therapies, 2019, } \\
\text { n.p. }\end{array}$ \\
\hline $\begin{array}{l}\text { Guide to Writing a Personal } \\
\text { Statement }\end{array}$ & $\begin{array}{l}\text { "Avoid references to your mental health. Such statements } \\
\text { could create the impression you may be unable to function } \\
\text { as a successful graduate student." }\end{array}$ & $\begin{array}{l}\text { Indiana University } \\
\text { - Purdue } \\
\text { University } \\
\text { Indianapolis, } \\
2019, \text { p. } 4\end{array}$ \\
\hline $\begin{array}{l}\text { Some Thoughts on Applying } \\
\text { to Graduate School in } \\
\text { Psychology }\end{array}$ & $\begin{array}{l}\text { "Never reveal personal struggles, family struggles, or } \\
\text { mental health problems in these statements." }\end{array}$ & $\begin{array}{l}\text { Yale Psychology, } \\
\text { 2019, p. } 5\end{array}$ \\
\hline $\begin{array}{l}\text { A Student's Perspective on } \\
\text { Applying to Graduate School } \\
\text { in (Clinical) Psychology: } \\
\text { A Step-by-Step Guide }\end{array}$ & $\begin{array}{l}\text { "It's called a 'personal statement,' but 'personal' does not } \\
\text { mean you should disclose sensitive or } \\
\text { inappropriately personal information (e.g., your own } \\
\text { diagnoses)." }\end{array}$ & $\begin{array}{l}\text { Choukas-Bradley, } \\
2011, \text { p. } 17\end{array}$ \\
\hline $\begin{array}{l}\text { Getting into Graduate School } \\
\text { in Psychology [PowerPoint] }\end{array}$ & $\begin{array}{l}\text { "Some potential No-No's } \\
\text { Mentioning your own mental health history/Mentioning } \\
\text { the mental health history of family/friends } \\
\text { A delicate balance." }\end{array}$ & $\begin{array}{l}\text { Sikorski, Mealy, } \\
\text { \& Fallon,_n.d., } \\
\text { slide } 30\end{array}$ \\
\hline $\begin{array}{l}\text { Eye on Psi Chi: Summer 2009: } \\
\text { Organizing Your } \\
\text { Personal Statement: An } \\
\text { Outline to Get You Started }\end{array}$ & $\begin{array}{l}\text { "Read Osborne (1996), and Appleby and Appleby (2007) } \\
\text { for advice about how to appropriately incorporate personal } \\
\text { information into your statement." }\end{array}$ & $\begin{array}{l}\text { Sleigh, 2009, p. } \\
17\end{array}$ \\
\hline $\begin{array}{l}\text { Applying to Doctoral Training } \\
\text { Programs in Clinical } \\
\text { Psychology: Writing an } \\
\text { Effective Personal Statement }\end{array}$ & $\begin{array}{l}\text { "We have read statements where applicants recounted } \\
\text { their own battles with addiction and recovery, their } \\
\text { struggles with manic-depressive disorder... While such life } \\
\text { experiences may well have influenced your decision to } \\
\text { pursue a Ph.D., the personal statement is not the time or } \\
\text { place to recount them...Your statement will be read by } \\
\text { academicians...they are skeptical of individuals whose } \\
\text { main motivation for entering the field is gaining a } \\
\text { perspective on some painful personal experiences." }\end{array}$ & $\begin{array}{l}\text { Forsyth \& } \\
\text { Wulfert, 1999, p. } \\
114\end{array}$ \\
\hline
\end{tabular}




\section{Setting a Research Agenda}

The apparent role of stigma in my scholarship rejection raises many questions. To what extent do my experiences generalize to others in clinical psychology? Are other applicants rejected from awards and school not because of their credentials but because of their disclosure of their SR-MH research? I address these questions below, and I describe how these questions can be tested using survey and experimental methods.

\section{How prevalent is stigma toward SR-MH research?}

As Table 1 suggests, there is circumstantial evidence that stigma toward SR-MH research is at least common enough for mentors to advise against its disclosure in the graduate school admissions process. It should be noted, though, these references are only graduate application resources offering advice; they do not represent application decisions by graduate committees. It is also important to emphasize that not everyone in academic psychology carries this stigma. Both of my mentors, for instance, encouraged me to disclose my personal links to my research area. Several renowned mental health researchers (e.g., Elyn Saks, Kay Redfield Jamison) have disclosed their SR-MH research, often with fears about sharing their mental illness (e.g., see Carey, 2011b). To estimate the prevalence of SR-MH research stigma, future work should document attitudes toward SR-MH research, while considering how different variables (e.g., career status, experience with mental illness, professional context) might moderate these attitudes.

\section{Is stigma toward SR research unique to MH?}

Stigma toward SR research appears to exist across other academic areas (Gardner et al. 2017). Observations indicate this stigma is especially pointed toward scholars who study marginalized communities (e.g., a transgender scholar studying transgender populations; Sumerau, 2016), suggesting SR-MH research may be one area that is especially affected. This would also suggest that stigma toward SR-MH research might correlate highly with stigma toward mental illness more broadly. It is therefore important to ascertain: what are the boundaries of stigma toward SR research? For what health conditions (mental vs. physical; invisible vs. concrete) is SR research disclosure acceptable, and in what contexts (e.g., personal statement; conference talk)? What reactions are associated with what health conditions?

For example, holding constant variables like professionalism and writing ability, would a graduate applicant who shares their connection to breast cancer be viewed as "oversharing" when compared to an applicant who shares their connection to suicide? Given that the public is generally more accepting, compassionate, and knowledgeable about physical conditions like breast cancer (Jorm, 2012), one hypothesis would be no. Perhaps, the applicant studying breast cancer would be viewed as noble, which would suggest a double-standard for SR-MH research, or perhaps not. Another example might compare how reactions to SR research on health conditions, mental or physical, compares to SR research on cultural characteristics (e.g., a member of a racial/ethnic minority group researching racial/ethnic minority health disparities). These examples are purely hypothetical, but they demonstrate the importance for professional psychology to clarify and be aware of such biases, if they exist, because the consequences have significant professional implications (e.g., rejection).

\section{What assumptions drive stigma toward SR-MH research and disclosure?}

In my story, the scholarship committee reportedly negatively viewed my disclosure of SR-MH research. The committee's views were, as I was informed, driven by the following assumptions: (1) that SR research obscures objectivity and (2) self-disclosure of SR research is unnecessary or adds no value in a professional setting. These assumptions are echoed in other accounts of biases against SR research 
(Bradley \& Nash, 2011; Killie, 2011; Gardner et al., 2017; Sumerau, 2016), but there may be other reasons that biases exist against SR research.

It is possible that the stigma toward SR-MH research largely stems from the general prejudice and stereotyping of mental illness, as people with mental illness may be viewed as "dangerous," "unstable," and "burdensome" (Parcesepe \& Cabassa, 2013). Relatedly, an admissions committee might question the applicant's judgment or ability to function if the applicant discloses their mental health problem. Indeed, the Indiana University - Purdue University Indianapolis's (2019) "Guide to Writing a Personal Statement states," "Avoid references to your mental health. Such statements could create the impression you may be unable to function as a successful graduate student" (p. 4). Ultimately, it would be beneficial to uncover what assumptions drive the extant stigma toward SR-MH research.

\section{Questioning Assumptions: Does SR Research Bias Objectivity?}

As outlined above, perceptions exist that SR research obscures objectivity. The rationale is that the pursuit of self-relevant topics may interfere with someone's ability to remain impartial when evaluating the findings (Gardner et al., 2017). While this issue remains an empirical question, it would be surprising if a SR researcher's questions and interpretations were not influenced by their lived experiences. However, this bias is not unique to SR research, and these biases do not prevent SR researchers from conducting ethical and rigorous research.

There are several notable mental health professionals who could be considered SR researchers. At age 68, Dr. Marsha Linehan, founder of Dialectical Behavior Therapy (DBT), came forward to the New York Times about her experiences with Borderline Personality Disorder (Carey, 2011a). Likewise, Kay Redfield Jamison, a prominent researcher on bipolar disorder, wrote An Unquiet Mind (Redfield Jamison \& Gardner, 1997) and documented her debilitating episodes with bipolar disorder. Other admirable examples include Jonathan Rottenberg (depression), Elyn Saks (schizophrenia), and Adi Jaffe (substance use). Should we suddenly distrust the integrity of these researchers because they have personal experience with their research area? How is conducting SR research so different from an academic testing their own (nonSR research) theory?

All research, to some extent, is shaped by a researcher's identity, intentions, and values, and researchers attempt to mitigate these biases through openness, transparency, and employing the scientific method (Patton, 2002). However, if there is stigma toward the pursuit of SR research, it is unlikely that researchers will be open and transparent about their perspectives. Thus, the field should question whether discouraging the disclosure of SR research achieves the goal of reducing bias.

\section{A Strengths-based Perspective}

This manuscript has proposed a research agenda for exploring the ostensible negative reactions toward SR-MH research. These negative reactions stem from an alleged negative view of SR-MH research. However, other researchers in the field of clinical psychology acknowledge the benefits of having people in the field who conduct SR research, and there are positive examples to illustrate this case. Put simply, SR-MH research should not be, and is not always, considered a kiss of death. I outline below why SR research in clinical psychology can benefit the field.

\section{Intrinsic motivation and passion}


People who conduct SR research may be more intrinsically motivated by their work. Intrinsic motivation refers to the natural inclination toward assimilation, mastery, spontaneous interest, and exploration of a task, and people with intrinsic motivation are more likely to find meaning in their work (Ryan \& Deci, 2000). To quote Marsha Linehan on her experience with BPD, "I was in hell. And I made a vow: when I get out, I'm going to come back and get others out of here” (Carey, 2011a, para 28).

\section{Insight and compassion for mental illness}

People with lived experience of mental illness may be in a unique position to develop research questions and have an understanding about their mental illness. This lived experience might be especially important for research settings, which may be distant from applied practice. Linehan, for instance, developed the therapeutic concept of Radical Acceptance, a core component of DBT, from her own treatment experiences (Carey, 2011a). Relatedly, mental health providers with a lived experience of mental illness commonly report that their experiences are helpful to their therapy work (Boyd, Zeiss, Reddy, \& Skinner, 2016).

\section{Decrease MH stigma through self-disclosure}

SR-MH researchers are in a powerful position to decrease stigma through disclosing their experiences. Recovery stories can effectively decrease stigma through humanizing people with mental illness, while providing hope to those experiencing mental illness (e.g., Coming Out Proud campaign; Corrigan et al., 2015). Acceptance of $\mathrm{MH}$ problems may also increase attitudes to seek treatment (Angermeyer, Matschinger, \& Schomerus, 2013). This may be especially relevant for academic settings, where roughly $40 \%$ of graduate students experience moderate levels of depression and anxiety (Evans, Bira, Gastelum, Weiss, \& Vanderford, 2018), with preliminary studies suggesting similar rates in faculty (Thomas, 2014). While it is compelling when academic role models like Linehan, Jaimison, Rottenberg, Saks, and Jaffe disclose their SR research, the decision to self-disclose should not be a privilege for only tenured professors or late-career researchers. Any researcher, at any career stage, can be an agent to decrease $\mathrm{MH}$ stigma.

\section{Conclusion}

The pursuit of SR research in clinical psychology should be viewed with nuance. SR research and SR research disclosure are not unequivocally good, and the field does not uniformly discriminate against SR research. Rather, the mental health field, including applicants, students, and faculty, would benefit to learn when, where, and how much the pursuit, or disclosure, of SR research is viewed negatively and positively. Moving forward, admissions committees might question whether SR research disclosure should be categorically viewed as a kiss of death (Appleby \& Appleby, 2006), considering that lived experiences can spawn creativity and passion for a research subject. I also recommend that SR research not be viewed as an inherently selfish pursuit, in which someone is primarily interested in learning about oneself. Some people who pursue SR research do so to help others in less powerful or underrepresented positions. Ironically, this manuscript falls under the definition of SR research. I was inspired to write this manuscript for fear that others were experiencing, unknowingly, stigma for disclosing their SR-MH research. I was also curious why clinical psychology, a field that treats psychopathology and seeks to decrease psychopathology stigma, would penalize prospective students from disclosing their experiences with a MH problem. My hope is that this commentary facilitates a scholarly discussion on this topic and motivates people to conduct empirical research to clarify this phenomenon. Ultimately, acceptance and disclosure of SR research in clinical psychology can be positive for students, scientists, and clients with mental illness, alike. 


\section{References}

Angermeyer, M. C., Matschinger, H., \& Schomerus, G. (2013). Attitudes towards psychiatric treatment and people with mental illness: Changes over two decades. The British Journal of Psychiatry, 203(2), 146-151.

Appleby, D. C., \& Appleby, K. M. (2006). Kisses of death in the graduate school application process. Teaching of Psychology, 33(1), 19-24.

Association for Behavioral and Cognitive Therapies (ABCT). (2019). Getting into Graduate School [Video file]. Retrieved from http://www.abct.org/Resources/?m=mResources\&fa=GettingGraduate

Boyd, J. E., Zeiss, A., Reddy, S., \& Skinner, S. (2016). Accomplishments of 77 VA mental health professionals with a lived experience of mental illness. American Journal of Orthopsychiatry, 86(6), 610.

Bradley, D. L., \& Nash, R. (2011). MeSearch and ReSearch: A Guide for Writing Scholarly Personal Narrative Manuscripts. IAP.

Carey, B. (2011a). Expert on mental illness reveals her own fight. The New York Times, 23.

Carey, B. (2011b). Memoir About Schizophrenia Spurs Others to Come Forward. The New York Times, 23.

Choukas-Bradley. (2011). A student's perspective on applying to graduate school in (clinical) psychology: A step-by-step guide [PDF]. Retrieved from https://liberalarts.utexas.edu/psychology/_files/PDF/diversitypdfs/A\%20Students\%20Perspective\%2 0on\%20Applying\%20to\%20Graduate\%20School\%20in\%20Clinical\%20Psychology.pdf

Evans, T. M., Bira, L., Gastelum, J. B., Weiss, L. T., \& Vanderford, N. L. (2018). Evidence for a mental health crisis in graduate education. Nature Biotechnology, 36(3), 282.

Forsyth, J. P., \& Wilfert, E. (1999). Applying to doctoral training programs in clinical psychology: Writing an effective personal statement. Behavior Therapist, 22, 113-115.

Gardner, S. K., Hart, J., Ng, J., Ropers-Huilman, R., Ward, K., \& Wolf-Wendel, L. (2017). "Mesearch:" Challenges and opportunities regarding subjectivity in knowledge construction. Studies in Graduate and Postdoctoral Education, 8(2), 88-108.

Indiana University - Purdue University Indianapolis (UIPUI) (2019). Guide to writing a personal statement [PDF]. Retrieved from https://psych.iupui.edu/sites/default/files/guidetowritingapersonalstatement_1.pdf

Jorm, A. F. (2012). Mental health literacy: Empowering the community to take action for better mental health. American Psychologist, 67(3), 231.

Killie, D. R. (2011). The psychology of "me": The pros and cons of research ideas that are central to the self. Psychological Science Agenda. Retrieved from:

https://www.apa.org/science/about/psa/2011/11/self-ideas

Langin, K. (2019). A wave of graduate programs drops the GRE application requirement. Science Magazine. Retrieved from https://www.sciencemag.org/careers/2019/05/wave-graduate-programsdrop-gre-application-requirement doi:10.1126/science.caredit.aay2093

Osborne, R. E. (1996, Fall). The "personal" side of graduate school personal statements. Eye on Psi Chi, $1(1), 14-15$.

Patton, M.Q. (2002), Qualitative research and evaluation methods, 3rd ed., Sage, Thousand Oaks, CA.

Parcesepe, A. M., \& Cabassa, L. J. (2013). Public stigma of mental illness in the United States: A systematic literature review. Administration and Policy in Mental Health and Mental Health Services Research, 40(5), 384-399. 
Prinstein, M. (2017). Mitch's uncensored advice for applying to graduate school in clinical psychology [PDF]. Applying to Graduate School in Clinical Psychology. Retrieved from http://mitch.web.unc.edu/files/2017/02/MitchGradSchoolAdvice.pdf

Prinstein, M. J., Choukas-Bradley, S. C., \& Guan, K. (2013). Deciding to apply and successfully gaining admission to graduate schools in psychology. In The Portable Mentor (pp. 13-44). Springer, New York, NY.

Redfield Jamison, K., \& Gardner, H. (1995). An unquiet mind: A memoir of moods and madness. Nature, 377(6550), 587-587.

Rüsch, N., Angermeyer, M. C., \& Corrigan, P. W. (2005). Mental illness stigma: Concepts, consequences, and initiatives to reduce stigma. European Psychiatry, 20(8), 529-539.

Ryan, R. M., \& Deci, E. L. (2000). Self-determination theory and the facilitation of intrinsic motivation, social development, and well-being. American Psychologist, 55(1), 68.

Sikorski, Mealy, \& Fallon. (n.d.). Getting into graduate school in psychology [PowerPoint Slides]. https://www.ccsu.edu/psychology/files/GETTINGINTOGRADUATESCHOOLINPSYCHOLOGYfa 17.pptx

Sleigh, M. J. (2009, Summer). Organizing your personal statement: An outline to get you started. Eye on Psi Chi, 13(4), 17-19.

Sumerau, J.E. (2016). Cisgender me-search. Inside Higher Ed. Retrieved from https://www.insidehighered.com/advice/2016/08/05/most-research-cisgender-scholars-can-bedefined-me-search-essay

Thomas, K. (2014, May 8). We don't want anyone to know, say depressed academics. The Guardian. Retrieved from https://www.theguardian.com/higher-educationnetwork/blog/2014/may/08/academics-mental-health-suffering-silence-guardian-survey

World Health Organization . (2017). Depression and other common mental disorders: Global health estimates. Retrieved from http://apps. who.int/iris/bitstream/10665/254610/1/WHO-MSD-MER2017.2-eng.pdf

Yale Psychology. (2019). Some thoughts on applying to graduate school in psychology [PDF]. Retrieved from https://psychology.yale.edu/sites/default/files/files/APPLYING\%20TO\%20GRADUATE\%20SCHO OL\%20IN\%20PSYCHOLOGY.PDF 